This is the author's final, peer-reviewed manuscript as accepted for publication. The publisher-formatted version may be available through the publisher's web site or your institution's library.

\title{
Multiparasitism of stink bug eggs: competitive interactions between Ooencyrtus pityocampae and Trissolcus agriope
}

Marzie Mohammadpour, M. Amin Jalali, J. P. Michaud, Mahdi Ziaaddini, Hamid Hashemirad

\section{How to cite this manuscript}

If you make reference to this version of the manuscript, use the following information:

Mohammadpour, M., Jalali, M. A., Michaud, J. P., Ziaaddini, M., \& Hashemirad, H. (2014). Multiparasitism of stink bug eggs: Competitive interactions between Ooencyrtus pityocampae and Trissolcus agriope. Retrieved from http://krex.ksu.edu

\section{Published Version Information}

Citation: Mohammadpour, M., Jalali, M. A., Michaud, J. P., Ziaaddini, M., \& Hashemirad, H. (2014). Multiparasitism of stink bug eggs: Competitive interactions between Ooencyrtus pityocampae and Trissolcus agriope. BioControl, 59(3), 279-286.

Copyright: (C) International Organization for Biological Control (IOBC) 2014

Digital Object Identifier (DOI): doi:10.1007/s10526-014-9565-z

Publisher's Link: http://link.springer.com/article/10.1007/s10526-014-9565-z

This item was retrieved from the K-State Research Exchange (K-REx), the institutional repository of Kansas State University. K-REx is available at http://krex.ksu.edu 
Multiparasitism of stink bug eggs: Competitive interactions between Ooencyrtus pityocampae and Trissolcus agriope 


\begin{abstract}
Females of Trissolcus agriope (Platygastridae) avoid host (Brachynema signatum) eggs parasitized by conspecifics or Ooencyrtus pityocampae (Encyrtidae), but females of the latter species will superparasitize and multiparasitize, although they mostly attack unparasitized eggs. Females of T. agriope were more efficient in the laboratory and parasitized more hosts in 24 and $48 \mathrm{~h}$. In multiparasitized hosts, O. pityocampae was a superior larval competitor and could complete also development as a facultative hyperparasitoid. When females of both species foraged together, T. agriope parasitized significantly more than O. pityocampae, about 50\%in both cases, although $O$. pityocampae almost doubled its parasitism rate as the exposure period was lengthened from $24 \mathrm{~h}$ to $48 \mathrm{~h}$. When O. pityocampae followed T. agriope in sequential foraging bouts, the former species successfully parasitized more hosts than the latter. The advisability of co-releases of both species to improve biological control of first generation $B$. signatum in Iranian pistachio orchards is discussed.
\end{abstract}

Key words biological control, Brachynema signatum, interspecific competition, intraguild interactions, Encyrtidae, Scelionidae

\title{
Introduction
}


The green stink bug, Brachynema signatum Jakovlev (Heteroptera:

Pentatomidae), is a key pest of pistachio production in Iran (Mehrnejad 2001). Feeding by B. signatum and other species of Pentatomidae on developing pistachio fruits causes significant direct damage in the form of epicarp lesions that can result in significant nut drop and quality issues (Daane et al. 2005). The bug is also a vector of the pathogenic yeast Nematospora coryli, the causal agent of 'stigmatomycosis', a destructive disease of pistachio in many countries (Michailides et al. 1990). Given environmental concerns regarding pesticide use in pistachio orchards, the use of natural enemies for biological pest control is a preferred approach to B. signatum management (Mehrnejad 2001). Egg parasitoids are especially attractive as potential biological control agents because they kill their hosts before they cause any feeding damage. Field surveys have revealed that several parasitoid species collectively cause significant parasitism of $B$. signatum eggs in Iran (Hashemi Rad 1999).

Trissolcus agriope Kozlov \& Lê (Hymenoptera: Scelionidae) is a specialist parasitoid of B. signatum eggs and the most abundant species in the pistachio orchards of Iran. Since it is relatively easily reared, it has been suggested as a candidate agent for augmentation biological control of B. signatum in pistachio (Hashemi Rad 2009). It is a solitary, proovigenic species; females emerge with a full complement of eggs and need not feed to oviposit (Hashemi Rad 1999). Another common parasitoid of B. signatum eggs is Ooencyrtus pityocampae (Mercet) (Hymenoptera: Encyrtidae), a polyphagous egg parasitoid that commonly attacks the pine processionary caterpillar, Thaumetopoea pityocampa (Denis and Schiffermfiller) (Lepidoptera: Thaumetopoeidae), in southern Europe (Masutti et al. 1993). Augmentation of O. pityocampae has benefited control of 
processionary caterpillar in young pine trees (Tiberi et al. 1994) and it is also found parasitizing eggs of $B$. signatum in Iran. This species is synovigenic; females emerge without mature eggs and engage in non-lethal host-feeding, consuming droplets of ooplasm that exude from host eggs following ovipositor insertion (Battisti et al. 1990). Ooencyrtus pityocampae is another potential biocontrol agent of B. signatum and a generalist species for which mass rearing protocols have been established (Schmidt and Kitt 1993; Tiberi et al. 1991). Although normally solitary, it will occasionally produce two offspring in one host and can also complete development as a facultative hyperparasitoid feeding on the larvae of other egg parasitoids within multiparasitized hosts when the latter are encountered in more advanced stages of development (Cusumano et al. 2012a).

Collections of B. signatum egg masses on pistachio trees conducted in Rafsanjan, the main pistachio-growing region of Iran, in the years 2011-2012 revealed hatching rates ranging from 0 - 48\% (mean $=21 \pm 2.74 \%$ ) with parasitoids emerging from 13 - 91\% (mean $=53 \pm 4.0 \%$ ) with an additional $24 \%$ of eggs non-viable and yielding neither hosts nor parasitoids (MM, unpublished). The dominant parasitoid in early spring was $T$. agriope, but its abundance gradually declined following the late spring appearance of $O$. pityocampae, with up to $50 \%$ of egg masses ultimately becoming co-parasitized by both species (MM, unpublished data). Trissolcus females use an oviposition pheromone to mark parasitized eggs (Rosi et al. 2001), whereas eggs parasitized by Ooencyrtus females have respiratory stalks protruding from the host chorion that can be used for discrimination (Takasu and Hirose 1988). Preliminary observations revealed $O$. pityocampae will attack eggs of B. signatum previously parasitized by T. agriope, 
although it strongly prefers unparasitized eggs. In contrast, T. agriope females unequivocally reject host eggs parasitized by either conspecifics or $O$. pityocampae. Numerous interspecific interactions between Trissolcus and Ooencyrtus spp. have been previously reported (Buschman and Whitcomb 1980; Corrêa-Ferreira 1986; CorrêaFerreira and Moscardi 1995; Ehler 2002; Hoffmann et al. 1991; Shepard et al. 1994, Cusumano et al. 2011). For example, Amarasekare (2000a; 2000b) studied competition and coexistence between Trissolcus murgantiae (Ashmead) and Ooencyrtus johnsonii (Howard) and found that both species in combination inflicted substantial mortality on eggs of Murgantia histrionica (Hahn) (Heteroptera: Pentatomidae). Nevertheless, few studies have directly examined the biological interactions between these genera that might either facilitate, or limit, their mutual compatibility as biocontrol agents. It has been proposed that biological control may be disrupted by negative interactions between natural enemies such as interference competition or facultative hyperparasitism if these interactions disadvantage the more effective primary parasitoid (Briggs 1993; Batchelor et al. 2005; 2006; Denoth et al. 2002; Rosenheim et al. 1995; Turnbull and Chant 1961). Given uncertainty as to the role of O. pityocampae in supplementing or interfering with B. signatum biological control by T. agriope, the present study was undertaken to determine (1) comparative rates of $B$. signatum egg parasitism by both parasitoid species acting alone; (2) the relative acceptability to O. pityocampae of host eggs previously parasitized by T. agriope; (3) which parasitoid species was superior in larval competition and; (4) the competitive outcomes of simultaneous or sequential host exploitation in multiparasitized hosts. 


\section{Materials and methods}

Insects

A colony of $B$. signatum was established from material collected from Russian thistle, Salsola kali L., in a pistachio orchard in Rafsanjan, Kerman province,

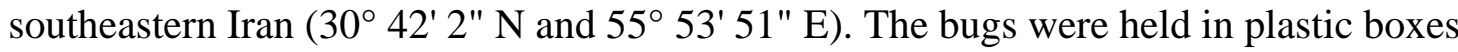
$(20.0 \times 30.0 \times 10.0 \mathrm{~cm})$ covered with mesh $(0.5 \mathrm{~mm}$ aperture $)$, in a climate-controlled room $\left(25.0 \pm 1.0{ }^{\circ} \mathrm{C}, 70 \pm 5 \% \mathrm{RH}\right.$ and 16:8 L:D photoperiod), and fed on a diet of $S$. kali and Syrian bean-caper, Zygophyllum fabago L., with water provided on a cotton wick. Food was changed every 1-2 days, and paper towels were provided as an ovipositional substrate. Egg masses were collected daily and eclosing immatures were held separately from adults. The colony was regularly augmented with field-collected material obtained from the same location.

Colonies of O. pityocampae and T. agriope were established from material collected with egg traps placed in the above-referenced pistachio orchard. These consisted of leaves containing egg masses of B. signatum obtained from the stock laboratory colony and stapled to yellow cards $(7.0 \times 7.0 \mathrm{~cm})$ which were then attached to S. kali plants at a height of $50.0 \mathrm{~cm}$ in various locations within non-commercial pistachio orchards. Others species collected included T. delucchii Kozlov, T. mitsukurii (Ashmead), T. semistriatus (Nees), T. oobius (Kozlov), T. deserticola (Kozlov), $T$. niceppe (Kozlov \& Lê), Psix saccharicola (Mani) and O. egeria Huang and Noyes. The identity of Encyrtidae was confirmed by Dr. John Noyes of the British Museum of 
Natural History and that of Scelionidae by Dr. N.F. Johnson of Ohio State University. Cards were collected every 3 days and parasitized eggs were held in an incubator at 27.0 $\pm 1.0^{\circ} \mathrm{C}, 65 \pm 5 \% \mathrm{RH}$, and 16:8 L:D photoperiod until wasps emerged. Adult parasitoids were isolated in glass vials $(1.5 \times 5.0 \mathrm{~cm})$ covered with tissue paper held in place with a rubber band, provided with a drop of diluted honey on the side of the vial, and held in an climate-controlled growth chamber under the physcial conditions described above. Egg masses of $B$. signatum were collected daily and each was exposed to a single parasitoid for $24 \mathrm{~h}$, then transferred to a clean glass tube for incubation. Male and female parasitoids were paired for mating within $48 \mathrm{~h}$ of adult emergence. Parasitoid females were all mated and used in experiments only once, those of O. pityocampae at 3-4 days of age, and those of $T$. agriope at 1 day. All experimental females were isolated in small vials (1.5 x 5.0 $\mathrm{cm}$ ) with a drop of diluted honey $24 \mathrm{~h}$ prior to use in an experiment.

\section{Solitary foraging}

Experimental egg masses were prepared by fastening 50 B. signatum eggs $(<24 \mathrm{~h}$ old) with honey to a piece of filter paper $(3.0 \times 2.0 \mathrm{~cm})$. Naturally occurring egg masses of $B$. signatum normally range from 10 to 40 eggs, but the intention was to provide a surfeit of eggs to improve resolution of species differences in parasitism potential. The experimental arena consisted of a plastic petri dish $(9.5 \mathrm{~cm}$ diameter) containing a $B$. signatum egg mass on filter paper. All egg masses were presented singly to naive females of each parasitoid species for periods of 24 and $48 \mathrm{~h}(\mathrm{n}=10$ for each treatment, except O. pityocampae for $48 \mathrm{~h}, \mathrm{n}=21$ ). The egg masses were then held in the growth chamber 
under the same physical conditions as the parasitoid colony until insects emerged and dead eggs could be recorded.

\section{Host egg discrimination}

To determine the relative acceptability of previously parasitized B. signatum eggs to O. pityocampae females, we presented individual females with egg masses parasitized $24 \mathrm{~h}$ previously by either conspecific or $T$. agriope females. The reverse experiment was not performed because preliminary tests revealed that T. agriope females reject $100 \%$ of eggs previously parasitized either by O. pityocampae or by conspecifics. Experimental egg masses were prepared by fastening a group of $10 \mathrm{~B}$. signatum eggs ( $<24 \mathrm{~h}$ old) with honey to a piece of filter paper $(3.0 \times 2.0 \mathrm{~cm})$ and then exposing them to a single female parasitoid in a test tube $(20.0 \times 3.0 \mathrm{~cm})$. Oviposition by $O$. pityocampae can be verified by the presence of egg stalks that protrude from the host chorion (Takasu and Hirose 1988), whereas parasitism by T. agriope produces a distinctive scar on the chorion. After the female had oviposited in all 10 eggs, the egg mass was removed and held under the same physical conditions as wasps until use in an experiment $24 \pm 2 \mathrm{~h}$ later. The experimental arena consisted of a plastic petri dish $(9.5 \mathrm{~cm}$ diameter) containing a $B$. signatum egg mass on filter paper. All egg masses used were presented singly to naive females of O. pityocampae ( $\mathrm{n}=20$ for each treatment) for period of $24 \mathrm{~h}$. After exposure, host eggs were examined under a dissecting microscope and the number of egg stalks counted to determine the number parasitized. The egg masses were then held in the 
growth chamber under the same physical conditions until insects emerged and dead eggs could be recorded.

\section{Simultaneous and sequential foraging}

To assess O. pityocampae host acceptance behavior in response to encounters with $T$. agriope females and host eggs they had recently parasitized, two additional experiments were conducted in which individual females of each species foraged either simultaneously or sequentially (O. pityocampae following T. agriope) within the same host patch consisting of 50 unparasitized B. signatum eggs, prepared as described above and presented in the same experimental arenas. In the first treatment, one female of each parasitoid species were released simultaneously in each replicate and permitted to forage for either $24 \mathrm{~h}(\mathrm{n}=6)$ or $48 \mathrm{~h}(\mathrm{n}=6)$. In the second treatment, a T. agriope female foraged on 50 B. signatum eggs for the first half of the exposure period, either $12 \mathrm{~h}(\mathrm{n}=$ 8) or $24 \mathrm{~h}(\mathrm{n}=11)$ and was replaced with an O. pityocampae female for the second half of the exposure period. After removal of wasps, egg masses were held in growth chambers under the same physical conditions as the wasp colony until emergence of insects.

Statistical analysis

Eggs that failed to hatch or yield a parasitoid were tallied as dead. All data passed Kolmogorov-Smirnov (K-S) test for normality and were therefore analyzed with 
parametric tests. A two-way ANOVA was used to analyze solitary foraging data with parasitoid species and exposure period as independent variables. Numbers of parasitoids emerging in the simultaneous and sequential foraging experiments were analyzed using a paired t-test, and total numbers of eggs parasitized (host eggs from which parasitoids emerged) and killed (host eggs which failed to hatch) during each exposure period were compared by one-way ANOVA.

\section{Results}

Solitary foraging

The two-way ANOVA revealed significant main effects of parasitoid species ( $F$ $=474.02$; d.f. $=1,47 ; \mathrm{P}<0.001)$, and exposure time $(F=30.71$; d.f. $=1,47 ; \mathrm{P}<0.001)$ on number of eggs parasitized, with a significant interaction term $(F=18.37$; d.f. $=1,47 ; \mathrm{P}<$ 0.001). Female T. agriope completely exploited the 50 hosts eggs in only 24 h (fig. 1). Whereas female $O$. pityocampae parasitized fewer than half the available host eggs in 24 h, that number increased by about $50 \%$ as the exposure period increased from 24 to 48 hours. There was no effect of exposure period on the number of host eggs killed for either species, but $T$. agriope killed more eggs than $O$. pityocampae $(\mathrm{F}=6.46$; d.f. $=1,49 ; \mathrm{P}=$ $0.014)$.

Host egg discrimination by O. pityocampae 
When female O. pityocampae were presented with host eggs parasitized $24 \mathrm{~h}$ earlier by a conspecific female, 14 of 20 females oviposited into a single host egg out of the 10 provided and the remaining 6 did not oviposit, for a mean of $0.65 \pm 0.11$ ovipositions per female. Of the 14 superparasitized eggs, 3 yielded 2 adults, 8 yielded a single adult, and 3 may have died as they occurred in clusters with a dead egg. In contrast, 15 of 20 females oviposited when presented with host eggs parasitized $24 \mathrm{~h}$ earlier by a $T$. agriope female for a mean of $1.15 \pm 0.21$ ovipositions per female, yielding significantly more ( $F=4.50$; d.f. $=1,38 ; P=0.040$ ) multiparasitism (oviposition into heterospecific-parasitized eggs) than superparasitism (oviposition into conspecific-parasitized eggs). Of the 23 multiparasitized eggs, 8 (34.8\%) yielded O. pityocampae adults and 15 died; the other 177 eggs all yielded T. agriope adults.

\section{Simultaneous and sequential foraging}

When females of each species foraged simultaneously in patches of 50 host eggs, twice as many T. agriope emerged as O. pityocampae following a $24 \mathrm{~h}$ foraging period, but only about $5 \%$ more after a $48 \mathrm{~h}$ foraging period (Table 1). Thus O. pityocampae emerged from more hosts when permitted a longer foraging period, whereas T. agriope emerged from similar numbers following both foraging periods. Although the total number of host eggs parasitized by both species increased from 24 to $48 \mathrm{~h}$, the number of host eggs killed was reduced by more than half. Comparable results were obtained in the sequential foraging experiment, except that $T$. agriope females successfully parasitized slightly less than $30 \%$ of hosts in both exposure periods (Table 2), compared to almost $50 \%$ in 
simultaneous foraging. When females of $T$. agriope preceded females of $O$. pityocampae on the same patch of 50 host eggs, the latter species emerged from 37\% more hosts when the exposure period was $24 \mathrm{~h}$ as opposed to $12 \mathrm{~h}$, whereas the number the former species emerged from similar numbers (Table 2). Once again, the total number of host eggs parasitized by both species increased from 24 to $48 \mathrm{~h}$, but the number of host eggs killed decreased.

\section{Discussion}

The results of the first experiment show that $T$. agriope is more efficient than $O$. pityocampae as a primary parasitoid of $B$. signatum eggs by virtue of parasitizing more eggs per unit time. Furthermore, O. pityocampae is a synovigenic species that does not carry a large number of mature eggs ready to lay (Battisti et al. 1990). Although $O$. pityocampae females appeared quite averse to superparasitism in the second experiment, they demonstrated some capacity for gregarious development with three cases of dual emergence. Other species of Ooencyrtus are known to be facultatively gregarious (e.g. Kidd and Amarsekare 2012) and superparasitism by O. pityocampae may be more prevalent in eggs of larger host species that permit the successful development of two progeny with higher probability. Female $O$. pityocampae were also reticent to attack host eggs parasitized by T. agriope females a day earlier, but they accepted them at a higher rate than conspecific-parasitized eggs and successfully parasitized them with a probability of slightly more than one in three. Results of the simultaneous and sequential foraging experiments further supported the inference that $O$. pityocampae is a relatively 
stronger competitor. Even though female T. agriope are able to fully exploit a patch of 50 host eggs in $24 \mathrm{~h}$ on their own (Fig. 1), they only succeeded in capturing approximately half of them when they foraged simultaneously with an O. pityocampae female (Table 1), and only about $30 \%$ when they were followed by an O. pityocampae female for a similar foraging period (Table 2). Some mutual interference could have impeded female performance in the simultaneous foraging experiment, but would not have influenced outcomes in the sequential foraging experiment.

Interestingly, the longer exposure periods which clearly favored O. pityocampae in multiparasitism experiments also resulted in significant reductions in the numbers of dead host eggs in both trials. Female T. agriope kill some host eggs in failed parasitism attempts (Fig. 1) and it is possible that $O$. pityocampae females were able to produce viable offspring in these eggs. This is not unusual for egg parasitoids that have little dependence on living host physiology (Grenier 1994). For example, Trichogramma nubilale Ertle and Davis (Hymenoptera: Trichogammitidae), can be reared on eggs of Maduca sexta (L.) (Lepidoptera: Sphingidae) that have been killed by UV-irradiation or freezing (Nagarkartti et al. 1991). Similarly, eggs of Riptortus pedestris (F.) (Hemiptera: Alydidae) killed by refrigeration are still viable hosts for Ooencyrtus nezarae Ishii (Abdul Alim and Lim 2011).

Alternatively, the host eggs killed in these experiments may represent examples of multiparasitized hosts in which mutual elimination of parasitoid larvae occurred. Even though intrinsic competition and facultative hyperparasitism are distinct ecological phenomena, they are both critically dependent on the time between ovipositions and often result in the death of the host and both competitors (Cusumano et al. 2012a). First instar 
larvae of T. agriope possess adaptations for the elimination of other larvae, including a ring of thoracic hairs used to propel them through the host ooplasm in search of competitors, and large sickle-shaped mandibles well suited for combat (Hashemi Rad 1999). In contrast, first instars of O. pityocampae have minute mandibles and remain attached to their respiratory stalks within the host egg, which limits their mobility (Masutti et al. 1993), although some Ooencyrtus species have been shown to inject substances during oviposition that can physiologically suppress the development of subsequent competitors (Cusumano et al., 2012b). However, the egg incubation period of T. agriope is very short (Hashemi Rad 1999) and its falcate mandibles are lost when it molts to the second instar, usually within 2-3 days of hatching. This molt yields the advantage to a first instar $O$. pityocampae larva that can either develop directly as a primary parasitoid if the T. agriope larvae is killed, or as a facultative hyperparasitoid on the living T. agriope larva if a large proportion of host resources have already been consumed. Thus, short periods between ovipositions favor $T$. agriope and may partly explain the reluctance of O. pityocampae females to multiparasitize. Longer periods between ovipositions increase the survival probability of O. pityocampae, but intermediate situations arise in which mutual elimination is possible, which could account for the larger number of dead eggs in the shorter exposure periods. This explanation is also consistent with the relatively higher parasitism rate by $T$. agriope in the simultanous compared to sequential multiparasitism experiments for both exposure periods, as the sequential exposures would have favored $O$. pityocampae by increasing the average time between ovipositions. The death of host eggs as a consequence of failed parasitism and/or multiparasitism will not contribute to the numerical response of either parasitoid 
population, but it may represent a significant contribution to biological control, given that 24\% of collected B. signatum eggs fail to yield either nymphs or parasitoids (MM unpublished).

Our results suggest that $T$. agriope is the superior extrinsic competitor, in terms of attacking hosts, whereas $O$. pityocampae is, on average, the superior intrinsic competitor, in terms of larval competition within the host (sensu Cusumano et al. 2012a). Nevertheless, the two species coexist and collectively inflict significant mortality on $B$. signatum egg masses. Stable coexistence despite competitive interactions has been noted between other Trissolcus - Ooencyrtus spp. causing significant mortality to pentatomid eggs (Amarasekare 2000a; 2000b). Kidd and Amarasekare (2012) modeled short-term versus long-term dynamics of Ooencyrtus and Trissolcus species parasitizing eggs of the harlequin bug, Murgantia histrionica (Hahn) incorporating a longer host handling time, but higher conversion efficieny (the number of parasitoids emerging divided by the number of host eggs attacked), for the latter. This model would predict that $O$. pityocampae conversion efficiency will decline with increasing host density, whereas that of $T$. agriope will be relatively unaffected (although the conversion efficieny of $O$. pityocampae will not be as great as that of $O$. johnsonii in the model because gregarious development is uncommon, at least in B. signatum). Also, the model would imply that the functional response of O. pityocampae should saturate at lower host egg densities than that of $T$. agriope, meaning that the latter species should inflict greater mortality at higher host densities. One contrast is that the Ooencyrtus species in our system exhibited the lower attack rate, whereas the Trissolcus species had the higher attack rate. So would augmentation of $O$. pityocampae in concert with T. agriope improve suppression of $B$. 
signatum, or exacerbate short term transient dynamics (as modeled by Kidd and Amarasekare 2012) to cause host population fluctuations incompatible with biological control?

One factor not considered in the above model is seasonality. There are between three and five generations of $B$. signatum annually in Iranian pistachio orchards, but it is the first generation that causes most economic damage while nuts are still immature. Total parasitism of $B$. signatum eggs is lowest during this first generation, but increases seasonally, with T. agriope dominating at first and being gradually joined, but never entirely displaced, by O. pityocampae. Clearly, coexistence between these parasitoids occurs naturally and is likely to persist with or without augmentation of either species, although the delayed seasonal appearance of both species, especially O. pityocampae, appears to limit their collective impact on the pest. Thus, we conclude that early season releases of both species have the potential to improve biological control by accelerating the system to its natural seasonal equilibrium, i.e., drawing forward high rates of egg parasitism (and significant ancillary egg mortality) to coincide with the first generation of B. signatum that inflicts the greatest economic losses in pistachio orchards.

\section{References}

Abdul Alim M, Lim UT (2011) Refrigerated eggs of Riptortus pedestris (Hemiptera: Alydidae) added to aggregation pheromone traps increase field parasitism in soybean. J Econ Entomol 104: 1833-1839 
Amarasekare P (2000a) Coexistence of competing parasitoids on a patchily distributed host: local vs. spatial mechanisms. Ecology 81: 1286-1296

Amarasekare P (2000b) Spatial dynamics in a host-multiparasitoid community. J Anim Ecol 69: 201-213

Batchelor TP, Hardy ICW, Barrera JF (2006) Interactions among bethylid parasitoid species attacking the coffee berry borer, Hypothenemus hampei (Coleoptera: Scolytidae). Biol Control 36: 106-118

Batchelor TP, Hardy ICW, Barrera JF, Pérez-Lachaud G (2005) Insect gladiators II: competitive interactions within and between bethylid parasitoid species of the coffee berry borer, Hypothenemus hampei (Coleoptera: Scolytidae). Biol Control 33: 194-202

Battisti A, Ianne P, Milani N, Zanata M (1990) Preliminary accounts on the rearing of Ooencyrtus pityocampae (Mercet)(Hym., Encyrtidae). J Appl Entomol 110: 121127

Briggs CJ (1993) Competition among parasitoid species on a stage-structured host and its effect on host suppression. Am Nat 141: 372-397

Buschman L, Whitcomb W (1980) Parasites of Nezara viridula (Hemiptera: Pentatomidae) and other hemiptera in Florida. Fla Entomol 63: 154-162

Correa-Ferreira SB (1986) Natural occurrence of the egg parasitoid complex of stink bugs on soybean in Parana, Brazil. An Soc Entomol Bras 5: 189-199

Correa-Ferreira SB, Moscardi F (1995) Seasonal occurrence and host spectrum of egg parasitoids associated with soybean stink bugs. Biol Control 5: 196-202 
Cusumano A, Peri E, Vinson SB, Colazza S (2011) Intraguild interactions between two egg parasitoids exploring host patches. BioControl 56: 173-184

Cusumano A, Peri E, Vinson SB, Colazza S (2012a) Interspecific extrinsic and intrinsic competitive interactions in egg parasitoids. BioControl 57: 719-734

Cusumano A, Peri E, Vinson SB, Colazza S (2012b) The ovipositing female of Ooencyrtus telenomicida relies on physiological mechanisms to mediate intrinsic competition with Trissolcus basalis. Entomologia Experimentalis et Applicata 143: $155-163$.

Daane KM, Yokota GY, Krugner R, Steffan SA, da Silva PG, Beede RH, Bentley WJ, Weinberger G (2005) Large bugs damage pistachio nuts most severely during midseason. Calif Agric 59: 95-102

de Pinero MDF (1977) Parasitisation of the eggs of Rhodnius prolixus by the microhymenopteran Telenomus costalimai and Ooencyrtus trinidadensis var. venatorius. Boletin de la Direccion de Malariologia y Saneamiento Ambiental 17: $131-139$

Denoth M, Frid L, Myers JH (2002) Multiple agents in biological control: improving the odds? Biol Control 24: 20-30

Ehler LE (2002) An evaluation of some natural enemies of Nezara viridula in northern California. BioControl 47: 309-325

Grenier S (1994) Rearing of Trichogramma and other egg parasitoids on artifical diets, pp. 73-92. In: Wajnberg E, . Hassan SA (ed) Biological control with egg parasitoids. CAB International, Wallingford, UK, 286pp. 
Hashemi Rad H (1999) Identification of egg parasitoid wasps of the green stink bugs (Brachynema spp. and Acrosternum spp.) and study of biology of Trissolcus agriope (Hym.: Scelionidae) in Rafsanjan. M.Sc. thesis, Shahid Chamran University of Ahvaz, Ahvaz, Iran.

Hashemi Rad H (2009) Study on Egg Parasitoids (T. agriope and Psix sp.) Using Eggs of Four Bug Species in Laboratory Conditions. V International Symposium on Pistachios and Almonds 912, Sanliurfa, Turkey

Hoffmann MP, Davidson NA, Wilson LT, Ehler LE, Jones WA, Zalom FG (1991) Imported wasp helps control southern green stink bug. Calif Agric 45: 20-22

Kidd D, Amarasekare P (2012) The role of transient dynamics in biological pest control: insights from a host-parasitoid community. J Anim Ecol 81: 47-57

Masutti L, Battisti A, Milani N, Zanata M, Zanazzo G (1993) In vitro rearing of Ooencyrtus pityocampae (Hym., Encyrtidae), an egg parasitoid of Thaumetopoea pityocampa (Lep., Thaumetopoeidae]. Entomophaga 38: 327-333

Mehrnejad M (2001) The current status of pistachio pests in Iran. Cahiers Options Méditerranéennes 56: 315-322

Michailides T, Morgan DP, Doster MA (1994) Diseases of pistachio in California and their significance. Acta Horticulturae 419: 337-344

Nagarkatti S, Giroux KJ, Keeley TP (1991) RearingTrichogramma nubilale (Hymenoptera: Trichogrammatidae) on eggs of the tobacco hornworm, Manduca sexta (Lepidoptera: Sphingidae). Entomophaga 36: 443-446

Rosenheim JA, Kaya HK, Ehler LE, Marois JJ, Jaffee BA (1995) Intraguild predation among biological-control agents: theory and evidence. Biol Control 5: 303-335 
Rosi MC, Isidoro N, Colazza S, Bin F (2001) Source of the host marking pheromone in the egg parasitoid Trissolcus basalis (Hymenoptera: Scelionidae). J Insect Physiol 47: 989-995

Schmidt GH, Kitt J (1993) Laboratory rearing of Ooencyrtus pityocampae in unfertilized and unlaid eggs of Thaumetopoea species. Naturwissenschaften 80: 379-380

Shepard BM, Elsey KD, Muckenfuss AE, Justo HD Jr (1994) Parasitism and predation on egg masses of the southern green stink bug, Nezara viridula (L.) (Heteroptera: Pentatomidae), in tomato, okra, cowpea, soybean, and wild radish. J Agric Entomol 11:375-381

Takasu K, Hirose Y (1988) Host discrimination in the parasitoid Ooencyrtus nezarae: the role of the egg stalk as an external marker. Entomol Exp Appl 47: 45-48

Tiberi R, Niccoli A, Roversi PF, Sacchetti P (1991) Laboratory rearing of Ooencyrtus pityocampae (Mercet) on eggs of Nezara viridula (L.) and other pentatomids. Redia 74: 467-469

Tiberi R, Niccoli, A., Sacchetti, P. (1994) Thaumetopoea pityocampa egg parasitism: modifications resulting from Ooencyrtus pityocampae augmentation. Atti XVII Congresso Nazionale Italiano di Entomologia, Udine, Giugno, Italy, pp. 13-18

Turnbull A, Chant D (1961) The practice and theory of biological control of insects in Canada. Can J Zool 39: 697-753 
Table 1. Mean ( \pm SE) numbers of Ooencyrtus pityocampae and Trissolcus agriope emerging, and numbers of host eggs killed, when females of each species foraged simultaneously as a pair on an artificial patch of 50 Brachynema signatum eggs. Numbers of emerging parasitoids of each species were compared by paired $t$-test for each exposure period and numbers of eggs parasitized and killed were compared between exposure periods by one-way ANOVA.

\begin{tabular}{|c|c|c|c|c|}
\hline \multirow[b]{2}{*}{$\begin{array}{l}\text { Exposure } \\
\text { period }\end{array}$} & \multicolumn{2}{|c|}{ " Parasitoid emerging } & \multirow[b]{2}{*}{ No. eggs parasitized } & \multirow[b]{2}{*}{ No. eggs killed } \\
\hline & O. pityocampae & T. agriope & & \\
\hline \multirow[t]{2}{*}{$24 \mathrm{~h}$} & $11.67 \pm 0.42$ & $23.17 \pm 0.75$ & $34.83 \pm 0.87$ & $15.17 \pm 0.87$ \\
\hline & $t=13.58, \mathrm{df}=$ & $5, \mathrm{P}<0.001$ & & \\
\hline \multirow[t]{2}{*}{$48 \mathrm{~h}$} & $20.50 \pm 0.62$ & $23.83 \pm 1.01$ & $44.33 \pm 1.05$ & $6.0 \pm 1.44$ \\
\hline & $t=2.91, \mathrm{df}=$ & $5, P=0.033$ & $F_{1,10}=39.72, \mathrm{P}<0.001$ & $F_{1,10}=29.72, \mathrm{P}<0.001$ \\
\hline
\end{tabular}


Table 2. Mean ( \pm SE) numbers of Ooencyrtus pityocampae and Trissolcus agriope emerging, and numbers of host eggs killed, when females of each species foraged in sequence (T. agriope $\rightarrow$ O. pityocampae) for the same period on the same artificial patch of 50 Brachynema signatum eggs. Numbers of emerging parasitoids of each species were compared by paired $t$-test for each exposure period and numbers of eggs parasitized and killed were compared between exposure periods by one-way ANOVA.

\begin{tabular}{|c|c|c|c|c|}
\hline \multirow[b]{2}{*}{$\begin{array}{l}\text { Exposure } \\
\text { period }\end{array}$} & \multicolumn{2}{|c|}{ Parasitoid emerging } & \multirow[b]{2}{*}{ No. eggs parasitized } & \multirow[b]{2}{*}{ No. eggs killed } \\
\hline & O. pityocampae & T. agriope & & \\
\hline \multirow[t]{2}{*}{$12 \mathrm{~h} \rightarrow 12 \mathrm{~h}$} & $18.75 \pm 0.45$ & $14.75 \pm 0.37$ & $33.50 \pm 0.46$ & $16.5 \pm 0.46$ \\
\hline & \multicolumn{2}{|c|}{$t=5.87, \mathrm{df}=7, \mathrm{P}=0.001$} & & \\
\hline \multirow[t]{2}{*}{$24 \mathrm{~h} \rightarrow 24 \mathrm{~h}$} & $20.50 \pm 0.62$ & $23.83 \pm 1.01$ & $40.27 \pm 1.06$ & $9.7 \pm 1.06$ \\
\hline & \multicolumn{2}{|c|}{$t=9.78, \mathrm{df}=10, \mathrm{P}<0.001$} & $F_{1,17}=26.52, \mathrm{P}<0.001$ & $F_{1,17}=26.52, \mathrm{P}<0.001$ \\
\hline
\end{tabular}




\section{Caption}

Fig 1 Mean numbers of $B$. signatum eggs parasitized or killed by individual females of Ooencyrtus pityocampae and Trissolcus agriope when exposed to 50 host eggs for either 24 or 48 h. Columns bearing the same upper case letters were not significantly different between species for a given exposure period (ANOVA, $\alpha>0.05$ ) and those bearing the same lower case number were not significantly different between exposure periods for a given species.

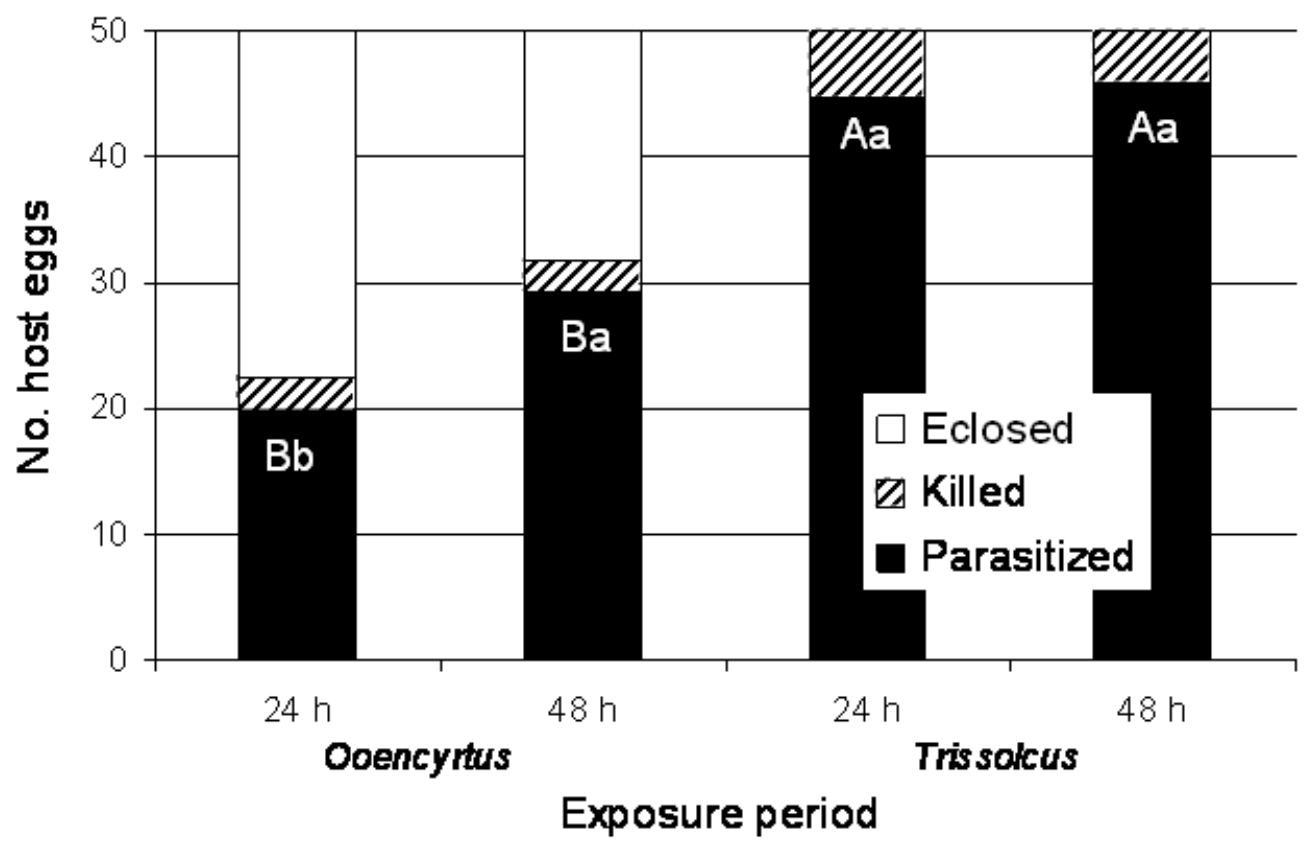

